\title{
Healthcare Service Quality Model of Private Hospitals in Bangkok, Thailand
}

\author{
Rungroje Songsraboon ${ }^{1}$, Jitravee Thongtao ${ }^{2}$, Phrapalad Somchai Damnoen ${ }^{3}$, Phrakhrubaidika \\ Theerayut Chantupamo ${ }^{4}$ \\ ${ }_{1,2}$ Siam University, Thailand. \\ ${ }^{3,4}$ Mahachulalongkornrajavidyalaya University, Thailand. \\ ${ }^{1}$ rrs101@ @otmail.com, ${ }^{2}$ jitravee@yahoo.com, ${ }^{3}$ somchai.dam@mcu.ac.th, ${ }^{4}$ mcuraiking@ gmail.com
}

\begin{abstract}
The objectives of this article are (1) to explore the perceived factors of service quality affecting the decision to use services in private hospitals, (2) to analyze the relationship of service quality models and the decision to use services in private hospitals, and (3) to develop service quality models that influence the decision to use services in private hospitals. The sample group was 400 patients who were admitted to private hospitals listed on the Stock Exchange of Thailand, by the convenience sampling method. The statistics used in this research were descriptive statistics, percentage, mean, and standard deviation. The correlation between factors was used to analyze one-way ANOVA and construct a multiple-linear regression equation by the stepwise method. The results of the research were found that 1) factors affecting the decision to use services in private hospitals consisted of 8 factors, namely service quality of doctors, service quality of nurses, service quality for diagnosis, service quality of reception, service quality to stay in private hospitals, service quality of patient foods, service quality of cleaning in patient rooms, and service quality of payments. 2) The regression equation of the service decision can have six independent variables into the regression equation. They were able to jointly explain $65.8 \%$ variation in service decision and the resulting regression equation has a variance of 0.378 .3 ) The results of the development of the service quality model by the multiple linear regression method using the stepwise method, the key factors were consistent with the empirical data. It has a good predictive ability with quadratic multiple correlations (R2) of 0.658 or $65.8 \%$, which can be written as a regression equation to be a key factor in the development of the service quality model that influence the decision to use services in private hospitals.
\end{abstract}

Index Terms

quality model, service, private hospital

Article Received: 10 August 2020, Revised: 25 October 2020, Accepted: 18 November 2020

\section{Introduction}

Good service is what the recipients are taken care of at the quality, standard, and are widely accepted. Standard of good service is defined by the word "quality" in which the present view is different from past understanding. The original quality is determined by the service provider, but nowadays, the judgment of the quality level has been changed to the accuracy required by the recipients, which quality will occur only when the recipient is in contact or have used that product or service. If the recipient perceives what received is equal or higher than what the recipient expects, the recipient will be satisfied and will lead to telling others about the perceived quality. On the other hand, if the recipient receives a product or service that is below expectations, the recipient will not be satisfied and refuse to use them. From the changing point of view of the definition of "quality", the consumer or the recipient has become the center of the business. Service recipients are entitled to choose to purchase or not to purchase [1]. As a result, agencies, organizations, and companies, whether public or private, are active to perceive the quality of their products or services from the perspective of their recipients, respecting and responding to their preferences, needs, and values of the patients and the decision to make the approach to healthcare [2].

Currently, the health services businesses in Thailand are likely to increase market competition. In 2015, ASEAN member countries will form the ASEAN Economic
Community. Advancing into the ASEAN Economic Community is an opportunity for economic growth and open opportunities for businesses that provide healthcare services, but at the same time, the impact of the ASEAN Economic Community may pose a threat to healthcare services businesses [3]. Therefore, private hospitals have to accelerate adaptation and accelerate the development of service quality to support the upcoming competition in the region and the preparation of private hospitals in Thailand to deal with more than 10 foreign funds, each with a minimum investment of US \$ 5 billion. This is especially true of the formation of Integrated Healthcare Holdings Sdn Bhd (IHH), a large fund of the Malaysian government, which aims to invest in the private hospital business and was listed on the Malaysian Stock Exchange and the Republic of Singapore Stock Exchange. Currently, Integrated Healthcare Holdings Sdn Bhd (IHH) is a hospital group with a market capitalization of 250 billion baht, which is an investment in the healthcare business with the total number 1 in the world. There are network hospitals in 6 countries: Malaysia, Republic of Singapore, Negara Brunei Darussalam, Turkey, People's Republic of China, and India, totaling 88 hospitals, with a total number of 12,000 beds, able to accommodate all ASEAN medical patients [3].

In 2012, Thailand had 3,009,169 foreigners in private hospitals, divided into 639,267 central regions, 175,534 northern regions, 89,784 northeastern regions, 208,985 south regions and Bangkok for 1,895,599 people (Table 1). Some popular services are dental treatment, plastic surgery, 
treatment of specific diseases such as cancer, brain surgery, heart disease, etc. [4].

Quality of Health Service in Private Hospitals Continuous improvement and development are needed. In order to increase the competitiveness and increase the quality of the recipients receiving treatment and referring to others to use the services. Healthcare lifestyle behaviors are the driving force behind private hospitals to improve service quality according to these changing behaviors. Sometimes the business operation of private hospitals cannot meet the recipient satisfaction as well as they should because of the lack of competent medical personnel, lack of impressive service, delayed service, lack of continuous quality improvement, and lack of quality of health service in private hospitals that are good and systematic. This causes each hospital to price war in order to create a decision to use services in private hospitals. This is a high investment that many entrepreneurs have suffered losses in their business operations. It eventually affects private hospital recipients that may receive poor quality health services because private hospitals may need to reduce the quality of medicines and reduce the rate of medical personnel, etc.

Therefore, this article will present the model of quality of health service in private hospitals in order to benefit the development of service quality on various sides. Including applying the results of this study to formulating marketing plans and advertising publicity to create a competitive advantage with hospitals abroad and support services for foreigners in order to make Thailand be a medical center in the ASEAN Economic Community.

\section{Research objectives}

1) To survey the perceived factors of service quality affecting the decision to use services in private hospitals.

2) To analyze the relationship of service quality and decision to use services in private hospitals.

3) To develop a service quality model that influences the decision to use services in private hospitals.

\section{Literature review}

Assael [5] gave the meaning of the perception that it is the process of a person to select, organize, and interpret stimuli until form the image of that thing. The perception of each consumer is different because perception is based on a person's needs, values, expectations that are important. Therefore, even in situations where stimuli are the same, each consumer will have different perceptions. Figure 4 shows the process of perception; there are elements of Assael, including perceptual selection, perceptual organization, and perceptual interpretation. From this idea, it was found that the processes that caused this perception are a lot of diversity, but in this study, the researchers linked cognitive processes to service quality based on Assael's cognitive thinking (1998). Zeithaml and Bitner had said that service quality is what determines the satisfaction or dissatisfaction of a consumer, which has five factors, related to the level of service quality and use it as a guideline for assessing the quality of services as follows.

1) Reliability refers to the ability to act independently of the service that the organization promises to the recipient of the reliability of the service, correct, and have the certainty of service every time, that means service recipients will be satisfied with every time they use the service.

2) Responsiveness refers to service personnel are willing to provide assistance and are ready to provide services to recipients in all matters.

3) Assurance refers to knowledge and expertise, modesty, beautiful manner in service of personnel, and competence of personnel in providing services that build trust, faith, and confidence to recipients.

4) Empathy refers to the efforts of the service provider to understand the needs of recipients and also manage to provide appropriate services, caring behavior, and understand the feelings and needs of recipients as well.

5) Tangibles refer to clearly the visible physical appearance of the premises, facilities, equipment, personnel, and communication equipment such as setting up and beautifying appropriate examination room decoration in accordance with the target audience, beautiful service provider's uniform clothing, suitable for the job description, and satisfying service recipients or decorating equipment to examine the patient's child to look like a toy in order to reduce the fear, including the availability of equipment to help facilitate various things while waiting, etc.

In the study of the perception of service quality be able to apply the concept of Zeithaml and Bitner [6], which offers a critical factor in the perception of service quality with a model called SERVQUAL, including reliability, response to recipients, assurance of confidence to recipients, caring for recipients and being tangible. In this study of quality perception, the researcher, therefore, adheres to the concept of Zeithaml and Bitner in determining the causal variables of this study.

Panjakajornsak [7] conducted research on "A Comprehensive Model Service Loyalty in The Context of Thai Private Hospitals". This research aimed to study the relationship between service quality, service value, patient satisfaction, and service loyalty [8], as measured by the behavioral intention of customers are: repurchase intentions, positive word of mouth, positive attitude, cross-buying intention. The willingness to pay for services at the premium price level by studying in 5 private hospitals listed on the Stock Exchange of Thailand. By quantitative research. Questionnaires were used from 2 groups of subjects, group 1, 102 undergraduate students in Bangkok, and 380 samples were collected from patients in 5 private hospitals to obtain data for the questionnaire and use of service quality measurement form with SERVPERF liker scale 7 levels. The analysis of the variables was analyzed by factor analysis from 13 service quality, the remaining 4 factors and the influence of variables, two-variable correlation analysis and LESREAL program for Structural Equation Modeling. The research results were found that service quality and service value have a strong correlation of 0.93 with service loyalty of the hospital. Service quality and patient satisfaction were associated with a high level of 0.92 with service loyalty. Hospital Service quality was directly related to 0.40 relationship with loyalty on the use of services of service loyalty of private hospitals.

It can be concluded that perception is the process of individuals examining their interests. To help make decisions about getting various services to achieve 
satisfaction with the service. Which in this research concluded the good service is a guideline that everyone must receive from the healthcare facility that they attend.

\section{Research method}

This research was survey research. The population used was the patients who were hospitalized in private hospitals listed on the Stock Exchange of Thailand.

The sample used in this study was hospital patients who were registered in the Stock Exchange of Thailand. In September 2013, 384samples were determined from the unidentified samples of W.G. Cochran. [9] The researcher then collected 400samples. Using multistage random sampling, the researcher performed a simple random sampling by random sampling of 16private hospitals listed on the Stock Exchange of Thailand [10]. The number of questionnaires was randomly conducted at 4locations: Krungthon Hospital (KDH), Ramkhamhaeng Hospital (RAM), Samitvej Hospital (SVH), and Vibhavadi Hospital (VIBHA). This was divided by quota and collected data with samples in each location by convenience Sampling.

The research tool was a questionnaire which was divided into 3 parts and 9 variables were used in the study as shown in Table 1.

Table 1 Research variables

\begin{tabular}{|l|l|}
\hline Independent variables & Dependent variables \\
\hline $\begin{array}{l}\text { Perception of service quality } \\
\text { of doctors (X1), Perception of }\end{array}$ & Decision to use \\
service quality of nurses & \\
(X2), Diagnostic Quality & \\
Perception (X3), Receptionist & \\
Quality Perception (X4), \\
Perception of quality of \\
occupancy in private \\
hospitals (X5), Perception of \\
food quality of patients (X6), \\
Perception of room care \\
quality (X7), Perception of \\
payment quality (X)
\end{tabular}

The statistics used in this research were descriptive statistics, namely percentage, mean, and standard deviation. The statistics used to find the quality of the questionnaire were based on Cronbach's alpha coefficient ( $\alpha$ Coefficient). Confidence test result $\alpha=0.908$. The reference statistic was used to find the correlation between factors using a One-Way ANOVA analysis, which determined a level of confidence that was significantly less than 0.05. Analysis of factors influencing the decision to use services in private hospitals, tested by multiple regression analysis (MRA) using stepwise.

\section{Research results}

1. Factors for the perception of service quality affecting the decision to use services in private hospitals including service quality of doctors, service quality of nurses, service quality for diagnosis, service quality of reception, service quality to stay in private hospitals, service quality of patient foods, service quality of cleaning in patient rooms, and service quality of payments, from figure 1 .

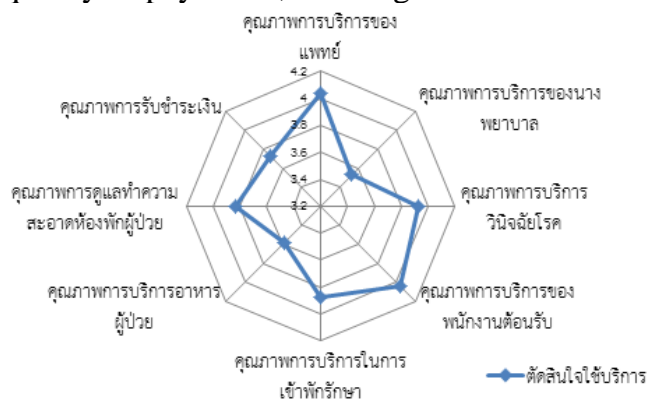

Figure 1: Service quality affecting the decision to use services in private hospitals

2. Analysis of the relationship of service quality and decision-making in private hospitals by using the One-Way ANOVA method, which determined the confidence level that was significantly less than 0.05 , it was found that the factors correlated with the decision to use services in private hospitals consisted of eight factors. The test results are shown in Table 3.

Table 2 Factors related to the decision to use services in private hospitals

\begin{tabular}{|l|l|l|l|}
\hline Factors & F & Significant & Result \\
\hline $\begin{array}{l}\text { Service quality of } \\
\text { doctors }\end{array}$ & 78.748 & .000 & Accept \\
\hline $\begin{array}{l}\text { Service quality of } \\
\text { nurses }\end{array}$ & 88.741 & .000 & Accept \\
\hline $\begin{array}{l}\text { Service quality for } \\
\text { diagnosis }\end{array}$ & 51.033 & .000 & Accept \\
\hline $\begin{array}{l}\text { Service quality of } \\
\text { reception }\end{array}$ & 188.780 & 000. & Accept \\
\hline $\begin{array}{l}\text { Service quality to stay } \\
\text { in private hospitals }\end{array}$ & 90.847 & 000. & Accept \\
\hline $\begin{array}{l}\text { Service quality of } \\
\text { patient foods }\end{array}$ & 25.604 & 000. & Accept \\
\hline $\begin{array}{l}\text { Service quality of } \\
\text { cleaning in patient } \\
\text { rooms }\end{array}$ & 122.693 & 000. & Accept \\
\hline $\begin{array}{l}\text { Service quality of } \\
\text { payments }\end{array}$ & 109.652 & 000. & Accept \\
\hline
\end{tabular}

3. The results of the development of the service quality model using the multiple linear regression equation by the Stepwise method. The key factors were consistent with the empirical data. It has a good predictive ability with quadratic multiple correlations $\left(\mathrm{R}^{2}\right)$ of 0.658 or $65.8 \%$, which can be written as a regression equation to be a key factor in the development of the service quality model, that influence the decision to use services in private hospitals as follows.

Service decision $=.308$, receptionist +.231 , paid service +.169 , patient room care +.144 , doctor's service +.144 , private hospital stays; +.108 . Patient food service; $\mathrm{R}^{2}=$ $0.658, \mathrm{SE}=0.378$. From the regression equation discovered above. Therefore, it can be written as a new quality model of health service in private hospitals (HSQ Model) from Figure 2. 


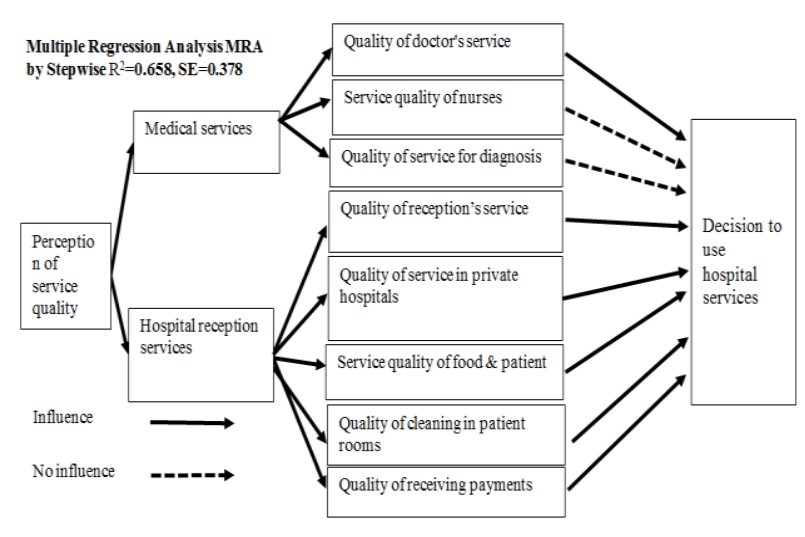

Figure 2: Model of service quality influencing decision to use in Private Hospitals (HSQ Model)

\section{Additional Research results}

1. Personal information of private hospital users found that most of the sample were male than female. Accounted for 59.20 and 40.8 percent, respectively, aged 36 - 45 years or 45.6 percent were self-employed accounted for 27.5 percent have a bachelor's degree representing $45.2 \%$ and having monthly income between $30,001-40,000$ baht or $41.6 \%$.

2. Analysis of factors related to the decision to use hospital services. It was found that the factors affecting the decision to use services in private hospitals consisted of 8 factors: service quality of doctors, service quality of nurses, service quality for diagnosis, service quality of reception, service quality to stay in private hospitals, service quality of patient foods, service quality of cleaning in patient rooms, and service quality of payments.

3. Regression equation using Stepwise method to be an important factor in the development of service quality models that influence the decision to use services in private hospitals. By using the independent variables into the equation of 8 variables, the regression equations of the service decision were obtained 6 independent variables were added to the regression equation, namely service quality of doctors, service quality of reception, service quality to stay in private hospitals, service quality of patient foods, service quality of cleaning in patient rooms, and service quality of payments, which the regression equation obtained they could jointly explain $65.8 \%$ variation in service decision and the resulting regression equation has a variance of 0.378 .

\section{Discussion of research results}

The results of the research showed that important factors affecting service decisions. It consisted of 6 variables: service quality of doctors, service quality of reception, service quality to stay in private hospitals, service quality of patient foods, service quality of cleaning in patient rooms, and service quality of payments [1]. These variables are an important factor affecting perception and decision making as research has found that perceptions of the quality of their products or services from the perspective of their recipients [2]. It is important to respect and respond to patient preferences, needs and values, and decisions about clinical guidelines, which offers a critical factor in the perception of service quality with a model called SERVQUAL[6] including reliability, reliability Response to service recipients, assurance of confidence to recipients, caring for service recipients, and being tangible.

Therefore, good service is a guideline that everyone must receive from the hospital that they serve to make an impression have confidence in service or trust and be trusted to serve next time.

\section{Suggestion}

1. There should be studies and development of service quality models and other additional factors.

2. There should be further studies and development of the service quality model of government and private hospitals.

3. There should be studies on marketing strategies. To know the weaknesses and strengths and the data from the aforementioned study will be used to further improve the weaknesses and strengthen the strengths of private hospitals

\section{References}

[1] A. Wangthong, A. Wangthong, T. Watsen, W. Suttarangsri, "Clients' Perspectives on Humanized Nursing Care within a Multicultural Context: A Case Study of Nongjik District, Pattani Province". Nursing Journal of the Ministry of Public Health. vol. 23 no. 3. pp. 35-44, 2014.

[2] R., Pelzang, "Time to learn: Understanding Patient-centered Care". British Journal of Nursing, Vol. 19 No. 14, pp. 912-917, 2010.
[3] ASEAN Economic Community Knowledge Information Center, "Integrated Healthcare Holdings Sdn Bhd (IHH)", 2013.

[4] National Statistical Office, Percentage of hospitals and private healthcare facilities With foreign outpatients receiving treatment by disease group, 2012. Retrieved June 3, 2013, from http://www.set.or.th/set/companyprofile.do ? symbol $=$ VIBHA\&language $=$ th $\&$ country $=$ TH Retrieved 3 June 2013, from http: //www.thai- aec.com(2013).

[5] H. Assale, "Consumer behavior and marketing action". (6th ed.). Ohio: SouthWestern College Publishing, 1998.

[6] A. Parasuraman, VA. Zeithaml, \& Berry. "Refinement and Reassessment of the 
SERVQUAL Scale". Journal of Retailing. vol. 67, no. 4, Winter, pp. 420-450, 1991.

[7] V. Panjakajornsak, "A Comprehensive Model Service Loyalty in The Context of Thai Private Hospitals". PhD., 2008.

[8] S. Rattanajarana, K. Karaked and R. Wongudom, "Nursing: The Perspectives of Hospitalized Patients". Journal of Nursing and Education. vol. 8 no. 4, pp. 140-152, 2015.

[9] J. Kamonwatin, "Perception of Internet Advertising on Consumer Product Purchase Decisions. In Bangkok and metropolitan area". Master of Management, Ramkhamhaeng University, 2013.

[10] The Stock Exchange of Thailand, Company / securities information. Retrieved 3 June 2013, from http://service.nso.go.th/nso/nso_center/proj ect/search/result_by_department-th.jsp, 2013. 